\title{
Thalamic deep brain stimulation for neuropathic pain after amputation or brachial plexus avulsion
}

\author{
*Erlick A. C. Pereira, D.M., ${ }^{1,2}$ Sandra G. Boccard, Ph.D., ${ }^{1}$ Paulo Linhares, M.D., ${ }^{2}$ \\ Clara Chamadoira, M.D., ${ }^{2}$ Maria José Rosas, M.D., ${ }^{2}$ Pedro Abreu, M.D., 2 \\ Virgínia Rebelo M.Psy., ${ }^{2}$ Rui Vaz, M.D., Ph.D., ${ }^{2}$ and Tipu Z. Aziz, F.Med.Sci. ${ }^{1,2}$ \\ ${ }^{I}$ Department of Neurosurgery and Nuffield Department of Surgery, Oxford University Hospitals, Oxford, \\ United Kingdom; and ${ }^{2}$ Departmento de Neurocirugia, Hospital de São João and Faculdade da Medicina, \\ Universidade do Porto, Portugal
}

Object. Fifteen hundred patients have received deep brain stimulation (DBS) to treat neuropathic pain refractory to pharmacotherapy over the last half-century, but few during the last decade. Deep brain stimulation for neuropathic pain has shown variable outcomes and gained consensus approval in Europe but not the US. This study prospectively evaluated the efficacy at 1 year of DBS for phantom limb pain after amputation, and deafferentation pain after brachial plexus avulsion (BPA), in a single-center case series.

Methods. Patient-reported outcome measures were collated before and after surgery, using a visual analog scale (VAS) score, 36-Item Short-Form Health Survey (SF-36), Brief Pain Inventory (BPI), and University of Washington Neuropathic Pain Score (UWNPS).

Results. Twelve patients were treated over 29 months, receiving contralateral, ventroposterolateral sensory thalamic DBS. Five patients were amputees and 7 had BPAs, all from traumas. A postoperative trial of externalized DBS failed in 1 patient with BPA. Eleven patients proceeded to implantation and gained improvement in pain scores at 12 months. No surgical complications or stimulation side effects were noted. In the amputation group, after 12 months the mean VAS score improved by $90.0 \% \pm 10.0 \%(\mathrm{p}=0.001)$, SF-36 by $57.5 \% \pm 97.9 \%(\mathrm{p}=0.127)$, UWNPS by $80.4 \% \pm 12.7 \%(\mathrm{p}<0.001)$, and BPI by $79.9 \% \pm 14.7 \%(\mathrm{p}<0.001)$. In the BPA group, after 12 months the mean VAS score improved by $52.7 \% \pm 30.2 \%(\mathrm{p}<0.001)$, SF-36 by $15.6 \% \pm 30.5 \%(\mathrm{p}=1.000)$, UWNPS by $26.2 \% \pm 40.8 \%(\mathrm{p}$ $=0.399)$, and BPI by $38.4 \% \pm 41.7 \%(\mathrm{p}=0.018)$. Mean DBS parameters were $2.5 \mathrm{~V}, 213$ microseconds, and $25 \mathrm{~Hz}$.

Conclusions. Deep brain stimulation demonstrated efficacy at 1 year for chronic neuropathic pain after traumatic amputation and BPA. Clinical trials that retain patients in long-term follow-up are desirable to confirm findings from prospectively assessed case series.

(http://thejns.org/doi/abs/10.3171/2013.7.FOCUS1346)

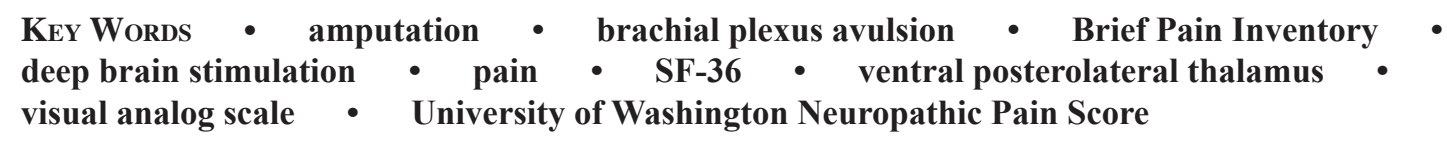

$\mathrm{P}$ Hantom limb pain is uncommon, with an incidence of 1-2 cases per 100,000 individuals, but presents a significant burden to the patient, affecting up to $85 \%$ of amputees. ${ }^{19}$ Stump pain usually occurs at some

\footnotetext{
Abbreviations used in this paper: $\mathrm{BPA}=$ brachial plexus avulsion; $\mathrm{BPI}=$ Brief Pain Inventory; DBS = deep brain stimulation; EFNS $=$ European Federation of Neurological Societies; MCS $=$ motor cortex stimulation; NICE = United Kingdom National Institute for Health and Clinical Excellence; SCS = spinal cord stimulation; SF-36 = 36-Item Short-Form Health Survey; UWNPS = University of Washington Neuropathic Pain Score; VAS = visual analog scale.

* Drs. Pereira and Boccard contributed equally to this work.
}

time during the first month following amputation and resolves in many patients after $2-3$ years without treatment, except in cases in which phantom pain develops. The incidence of phantom pain is variable but increases with more proximal amputations. The origin and pathophysiological mechanisms of phantom pain are not clearly defined. However, both peripheral and central neural mechanisms have been described, along with superimposed psychological mechanisms. The management of phantom limb pain has little evidence base in the scientific literature; while numerous treatments have been described, there is little clinical evidence supporting any particular therapy. 


\section{E. A. C. Pereira et al.}

Brachial plexus avulsion (BPA) commonly results in early deafferentation pain, with $25 \%$ of sufferers going on to experience severe neuropathic pain several years later that is usually refractory to pharmacotherapy ${ }^{45}$ Brachial plexus avulsion pains have been dichotomized into either continuous, often burning or throbbing pain and likely involving thalamic neuroplasticity, or shooting paroxysms associated with dorsal horn hyperactivity. ${ }^{48,49}$ Both phantom limb pain after amputation and deafferentation pain after BPA fulfill a recently revised definition of neuropathic pain as pain caused by a lesion or disease of the somatosensory system. ${ }^{27}$ Neuropathic pain symptom severity and duration are often greater than other forms of chronic pain, leading patients and clinicians to consider neurosurgery. ${ }^{59}$

Deep brain stimulation (DBS) is an invasive neurosurgical intervention established in movement disorders and also used to treat "off-label" clinical indications of epilepsy, Tourette syndrome, obsessive-compulsive disorders, depression, and cluster headache..$^{51}$ Deep brain stimulation has been performed for more than half a century for chronic pain amelioration, ${ }^{21}$ its use preceding gatecontrol theory by a decade. ${ }^{43}$ After rodent self-stimulation experiments and reported analgesia in patients receiving septal DBS, ${ }^{47}$ cancer pain was being relieved by intermittent stimulation by the $1960 \mathrm{~s} .{ }^{16,22}$ Evidence supporting the ventroposterolateral nucleus of the sensory thalamus (ventroposterolateral) as a target for limb pain came from ablative surgery. ${ }^{41}$ The ventroposterolateral nucleus of the sensory thalamus has been targeted successfully for 4 decades, ${ }^{25}$ as has periaqueductal and periventricular gray matter. ${ }^{57}$

Two multicenter trials of DBS for pain were conducted to seek US FDA approval. ${ }^{7}$ Neither trial satisfied efficacy criteria of at least half of the patients reporting at least 50\% pain relief 1 year after surgery. United States FDA approval was therefore not sought. Deep brain stimulation for pain was decreed "off label," precluding medical insurance reimbursement. Consequently, few surgeons currently report DBS for pain outside of Europe, where it has approval by the European Federation of Neurological Societies (EFNS) and the United Kingdom National Institute for Health and Clinical Excellence (NICE), ${ }^{9,46}$ Nevertheless, a recent growing interest in its use for chronic pain refractory to medical treatment has paralleled advances in DBS technology, neuroimaging, and the publication of more rigorous case series regarding its long-term efficacy. Successful results have been shown for multiple origins of pain, in particular for poststroke pain, face pain, amputation, and BPA. ${ }^{5}$

In this paper we describe a prospectively studied, open-label, consecutive case series of patients receiving ventroposterolateral DBS for chronic neuropathic pain after amputation or BPA. These patients were treated at a single Portuguese center that was establishing DBS for pain service after a decade's experience of using DBS for movement disorders in more than 200 patients. Improvements in patient-reported outcome measures of pain and quality of life were analyzed, and challenges to DBS for pain are discussed.

\section{Methods}

\section{Study Population}

Patients were referred by clinicians nationally (in Portugal) to a single-center multidisciplinary team consisting of pain specialists, neurologists, neuropsychologists, and neurosurgeons at Hospital de São João in Porto, Portugal. Neuropsychological evaluation excluded psychiatric disorders and ensured minimal cognitive impairment. Neuropathic medications and other surgical treatments may have been attempted with limited success. Selection criteria included neuropathic pain refractory to medicines for at least 2 years, together with absence of surgical contraindications such as coagulopathy or ventriculomegaly. Informed consent was obtained and the study received local ethical board approval. Patients were counseled for the possibility that they may derive no benefit from ventroposterolateral DBS or not tolerate it well, necessitating its removal.

\section{Deep Brain Stimulation Procedure}

For surgery, a Leksell stereotactic frame (Elekta Instruments) was applied to the patient's shaved head under local anesthesia. A stereotactic head CT scan with a 2-mm slice thickness was performed, with preoperative T1- and T2-weighted MR images of 2-mm slice thickness from a 1.5-T scanner volumetrically fused to the scan using FrameLink stereotactic calculation software (Medtronic). The Leksell stereotactic arc was then fixed to its frame on the awake, semisitting patient. Intravenous vancomycin and cefotaxime antibiotic prophylaxis and dexamethasone were routinely administered before surgery commenced. After bur hole exposure, a Leksell radiofrequency electrode impedance check was performed to $10 \mathrm{~mm}$ above target, then DBS electrode insertion to target, and intraoperative $\mathrm{C}$-arm radiographic target confirmation.

A guiding principle in awake electrode targeting is the established somatotopic organization of the somaesthetic thalamic nuclei. Human microelectrode studies have revealed a mediolateral somatotopy in the contralateral ventral posterior thalamus, with the head of the homunculus medial and the feet lateral. ${ }^{34}$ The contralateral ventroposterolateral nucleus of the sensory thalamus was targeted for limb pain and found in the plane $10-13 \mathrm{~mm}$ posterior to the midcommissural point, and from $5 \mathrm{~mm}$ below to $2 \mathrm{~mm}$ above it. The arm area of the ventroposterolateral nucleus of the sensory thalamus was $2-3 \mathrm{~mm}$ medial, and leg area 1-2 mm medial, to the internal capsule. Thus, targeting was generally $12-14 \mathrm{~mm}$ lateral and $0-2 \mathrm{~mm}$ anterior to the posterior commissure. A transfrontal extraventricular trajectory from an entry point on or near the coronal suture to the ipsilateral ventroposterolateral nucleus of the sensory thalamus was planned, avoiding blood vessels and sulci.

Targets were implanted with Medtronic Model 3387 quadripolar electrodes with $0.5-\mathrm{mm}$ contacts spaced 1.5 $\mathrm{mm}$ apart. Final electrode position was determined by intraoperative clinical assessment that relied upon subjective reporting by the awake patient rather than microelec- 


\section{Deep brain stimulation for amputation and brachial plexus pain}

trode recording. Tactile stimulation of the painful body part was performed intraoperatively to augment pain and assess response if necessary. At either target during surgery, DBS at lower frequencies $(\leq 50 \mathrm{~Hz})$ was analgesic and higher frequencies $(>70 \mathrm{~Hz})$ hyperalgesic. Bipolar stimulation of $5-50 \mathrm{~Hz}$ was performed initially, with a pulse width of 200-450 $\mu$ s and amplitude of $0.5-5 \mathrm{~V}$. Stimulation of the ventroposterolateral nucleus of the sensory thalamus aimed to supplant painful sensation by pleasant paresthesias. Adjustment was primarily somatotopic, with the assessor alert to pyramidal signs suggesting capsular involvement. The electrode was rarely moved from its planned target, but occasionally moved $2 \mathrm{~mm}$ at a time lateral, medial, proximal, or distal during awake testing to optimize somatotopic coverage. Once satisfactory targeting had been achieved by microdrive adjustment, the patient's electrode was secured in place with a Stimloc skull fixation device (Medtronic). Electrode leads were externalized parietally via temporary extensions, and electrode position was confirmed by postoperative stereotactic CT, again fused to preoperative MRI. Typical surgery duration was 2-3 hours, including stereotactic planning.

Bedside DBS programming was undertaken during the postoperative period both morning and afternoon, in sessions lasting approximately 30 minutes per patient. Different frequencies from 5 to $50 \mathrm{~Hz}$ were used alongside varied bipolar stimulation over different contacts at increasing pulse widths and amplitudes to optimize analgesia without unpleasant sensations in the painful body part. Typically, pleasant paresthesia was elicited and occasionally analgesia without paresthesia, mirroring intraoperative results (Video 1).

VIDEO 1. Clip showing a postoperative patient with BPA pain who underwent a trial of externalized DBS, describing pain improvement. Copyright Erlick A. C. Pereira. Published with permission. Click here to view with Windows Media Player. Click here to view with Quicktime.

After 48 hours of postoperative clinical assessment, a decision was made whether to permanently implant the electrodes under general anesthesia. The electrodes were connected to a pulse generator (Medtronic Kinetra or Activa PC) implanted in the chest via new extension leads. During postoperative assessment, each patient recorded visual analog scale (VAS) scores at least twice daily at set times while blinded to DBS settings. Targets were tested using analgesic stimulation parameters to determine which electrode contacts conferred maximum analgesia. Visual analog scale scores were averaged for the trial period and compared with preoperative scores to assess for improvement. The decision to proceed to implantation of the pulse generator was made for each individual patient, guided by the multidisciplinary team.

Patients ideally left the hospital a day after implantation of the pulse generator, with progress followed up by clinic appointments at 1,3, and 6 months, and then yearly thereafter. Continuous rather than on-demand stimulation was encouraged, but in addition to the ability to switch the DBS on and off at will, patients were usually given control over its voltage only, which was typically limited by the clinician to a maximum amplitude of $4 \mathrm{~V}$.

\section{Outcome Assessment}

Quantitative assessment of pain and health-related quality of life were performed 1 month before surgery and postoperatively at 1,3 , and 6 months, and then annually by independent, blinded assessors trained in pain medicine but not involved in caring for the patient and unaware of the details of the neurosurgical treatment given. The VAS to rate pain intensity, the University of Washington Neuropathic Pain Score (UWNPS), and Brief Pain Inventory (BPI) were used. ${ }^{6,14}$ Patients recorded VAS scores twice daily in a pain diary over 14 days. The 28 VAS scores were reviewed to ensure consistency, and the mean was then calculated.

Patients also completed a 36-Item Short-Form Health Survey (SF-36) on quality of life along with the pain questionnaires. The SF-36 responses were regrouped into 8 domains of physical functioning: role (physical), bodily pain, general health, vitality, social functioning, role (emotional), and mental health. Results were scored by online tools (http://www.sf-36.org/demos/sf-36.html). Norm-based scores allowed comparison between studies.

\section{Statistical Analysis}

As pain assessments were made as repeated measures throughout the follow-up, preoperative and postoperative scores were compared for each group of patients using a general linear mixed model, with a p value $<0.05$ considered statistically significant and $\mathrm{p}<0.01$ considered highly significant.

\section{Results}

Table 1 lists the demographic characteristics of 12 consecutive patients treated over 3 years with DBS surgeries between January 2009 and May 2011, including pain origin, relevant preoperative medications, stimulation parameters, and baseline preoperative and long-term (12-month) postoperative VAS scores. Ten patients (83\%) were male, 2 female (17\%), and the mean age of the study population was $53.6 \pm 9.8$ years old. All patients suffered traumatic injuries, and only 1 was not due to a motor vehicle accident. All amputees experienced phantom pain and all BPAs had preganglionic involvement. No patients with BPA underwent amputations and no amputees had BPA. The mean duration of symptoms before surgery was $20 \pm 13.4$ years. One patient with BPA underwent an unsuccessful postoperative trial of externalized DBS due to lack of efficacy despite intraoperative paresthesia. Eleven patients proceeded to full DBS implantation after successful intraoperative and postoperative trials and completed postoperative follow-up duration of 1 year. There were no significant surgical complications in this series and side effects from stimulation were unremarkable. No patients have required electrode or implantable pulse generator revisions to date (as of June 2013). All patients received continuous bipolar DBS with patient control of amplitude up to a clinician-set maximum.

Tables 1 and 2 also summarize baseline patient-reported outcome measures for those patients proceeding to full implantation of the DBS system. There were no sta- 
E. A. C. Pereira et al.

TABLE 1: Patient demographics, stimulation parameters, and baseline preoperative and long-term postoperative pain scores*

\begin{tabular}{|c|c|c|c|c|c|c|c|c|c|c|}
\hline Case No. & $\begin{array}{l}\text { Age at Op } \\
\text { (yrs), Sex }\end{array}$ & Pathology & $\begin{array}{c}\text { Symptom } \\
\text { Duration (yrs) }\end{array}$ & $\begin{array}{c}\text { Preop } \\
\text { Medications }\end{array}$ & $\begin{array}{l}\text { Year of } \\
\text { Surgery }\end{array}$ & $\begin{array}{l}\text { Amplitude } \\
\text { (V) }\end{array}$ & $\begin{array}{c}\text { Frequency } \\
(\mathrm{Hz})\end{array}$ & $\begin{array}{c}\text { Pulse } \\
\text { Width }(\mu s)\end{array}$ & $\begin{array}{l}\text { Preop VAS } \\
\text { Score }\end{array}$ & $\begin{array}{c}\text { 12-Mo Postop } \\
\text { VAS Score }\end{array}$ \\
\hline 1 & $63, \mathrm{M}$ & It BPA & 4 & PGB & 2009 & 3.0 & 50 & 210 & 8 & 2 \\
\hline 2 & $45, M$ & It BPA & 28 & PGB & 2009 & 3.0 & 25 & 210 & 10 & 7 \\
\hline 3 & $71, \mathrm{~F}$ & rt AKA & 13 & PGB & 2009 & 1.5 & 20 & 300 & 4 & 0 \\
\hline 4 & $64, \mathrm{M}$ & It BPA & 50 & PGB & 2009 & 1.5 & 10 & 210 & 9 & 4 \\
\hline 5 & $45, M$ & It $A E A$ & 25 & PGB & 2009 & 1.0 & 10 & 90 & 9 & 6 \\
\hline 6 & $57, \mathrm{~F}$ & It BKA & 24 & PGB, GBP & 2010 & 3.5 & 20 & 210 & 5 & 1 \\
\hline 7 & $40, M$ & It BPA & 14 & PGB, GBP & 2010 & 4.0 & 40 & 300 & 9 & 0 \\
\hline 8 & $48, M$ & rt AEA & 16 & PGB & 2010 & 3.3 & 10 & 210 & 9 & 7 \\
\hline $9 \dagger$ & $45, M$ & It BPA & 12 & PGB, TMD, AMT & 2010 & NA & NA & NA & 9 & 9 \\
\hline 10 & $50, M$ & It AKA & 20 & GBP, TMD & 2011 & 3.5 & 30 & 210 & 10 & 1 \\
\hline 11 & $56, \mathrm{M}$ & rt BPA & 2 & TMD, DZP & 2011 & 1.0 & 30 & 180 & 6 & 0 \\
\hline 12 & $52, \mathrm{M}$ & It BPA & 32 & $\begin{array}{l}\text { PGB, GBP, TMD, } \\
\text { AMT }\end{array}$ & 2011 & 1.5 & 30 & 210 & 10 & 4 \\
\hline mean \pm SD & $53 \pm 10$ & & $20 \pm 13$ & & & $2.4 \pm 1.1$ & $25 \pm 13$ & $213 \pm 56$ & $8.2 \pm 2.0$ & $3.4 \pm 3.2$ \\
\hline
\end{tabular}

* $\mathrm{AEA}=$ above elbow amputation; $\mathrm{AKA}=$ above knee amputation; $\mathrm{AMT}=$ amitriptyline; $\mathrm{BKA}=$ below knee amputation; $\mathrm{DZP}=$ diazepam; $\mathrm{GBP}=$ gabapentin; $\mathrm{NA}=$ not applicable; $\mathrm{PGB}=$ pregabalin; $\mathrm{TMD}=$ tramadol.

$\dagger$ Failed trial of DBS.

tistically significant differences in baseline characteristics between pain etiologies. Figure 1 illustrates baseline scores and improvements across the entire 11-patient cohort for all outcome measures. At 1 month after surgery, mean VAS score improved by $60.1 \% \pm 27.3 \%(p<0.001)$, SF-36 improved by $30.1 \% \pm 75.5 \%(\mathrm{p}=0.553)$, UWNPS improved by $47.1 \% \pm 37.1 \%(\mathrm{p}<0.001)$, and BPI improved by $51.4 \% \pm 33.3 \%(\mathrm{p}<0.001)$. Throughout the first year, mean pain relief was sustained, and at 12 months the VAS score was improved from before surgery by $69.6 \% \pm$ $29.6 \%$ ( $\mathrm{p}<0.001)$, SF-36 improved by $34.6 \% \pm 69.1 \%$ ( $\mathrm{p}=$ $0.093)$, UWNPS improved by $50.8 \% \pm 41.2 \%$ ( $<<0.001)$, and BPI improved by $57.3 \% \pm 37.8 \%(\mathrm{p}<0.001)$.

Although both amputation and BPA subgroups showed significant improvements initially with DBS sustained for 1 year (Table 3, Figs. 2 and 3), amputation pain improved the most, with benefits sustained across all pain outcome measures. The BPA pain improvements in overall outcome scores were restricted to the VAS. In the amputation group, after 12 months the mean VAS score improved by $90.0 \% \pm 10.0 \%$ ( $\mathrm{p}<0.001)$, SF-36 improved by $57.5 \% \pm 97.9 \%(\mathrm{p}=0.127)$, UWNPS improved by $80.4 \%$ $\pm 12.7 \%(\mathrm{p}<0.001)$, and BPI improved by $79.9 \% \pm 14.7 \%$ ( $\mathrm{p}<0.001)$. In the BPA group, after 12 months the mean VAS score improved by $52.7 \% \pm 30.2 \%(\mathrm{p}<0.001)$, SF-36 improved by $15.6 \% \pm 30.5 \%(\mathrm{p}=1.000)$, UWNPS improved by $26.2 \% \pm 40.8 \%(\mathrm{p}=0.399)$, and BPI improved by $38.4 \% \pm 41.7 \%(\mathrm{p}=0.018)$.

Despite considerable improvements in pain scores, statistically significant overall improvements in SF-36 were not observed, with the exception of amputation pain 1 month after surgery, which improved by $71.4 \% \pm 98.1 \%$ $(\mathrm{p}=0.013)$. However, analyses of SF-36 subscores across the entire cohort demonstrated significant and sustained improvements in bodily pain ( $\mathrm{p}<0.001$ throughout) and physical functioning ( $\mathrm{p}=0.08$ at 6 months), with improvements in physical role and general health also approaching statistical significance. In contrast to anecdotal patient reports (Video 1), social functioning, vitality, and emotional and mental health were not significantly improved. Highly significant improvements $(\mathrm{p}<0.001)$ were observed in most UWNPS subscores including sharp, hot, intense, dull, deep, and unpleasant pain, but not cold, sensitive, and itchy pain. Statistical analyses of these subscores by etiological subgroup was not performed to avoid Type I errors, although considerable reductions in hot, sharp, deep, and dull UWNPS subscores in both amputation and BPA pain subgroups suggest DBS relieved both the continuous and paroxysmal components of neuropathic pain. The BPI improvements were statistically

TABLE 2: Baseline preoperative patient-reported outcome measure results*

\begin{tabular}{lrrrr}
\hline \multicolumn{1}{c}{ Group } & \multicolumn{1}{c}{ VAS } & \multicolumn{1}{c}{ SF-36 } & UWNPS & BPI \\
\hline amputation & $7 \pm 2.8$ & $1048.6 \pm 191.2$ & $72.2 \pm 17.3$ & $13.6 \pm 3.8$ \\
BPA & $9 \pm 0.6$ & $1160.8 \pm 203.0$ & $62.3 \pm 14.3$ & $13.5 \pm 1.9$ \\
overall & $8.2 \pm 2.0$ & $1109.9 \pm 196.9$ & $66.8 \pm 15.8$ & $13.6 \pm 2.8$ \\
\hline
\end{tabular}

* All values reported as mean $\pm \mathrm{SD}$. 

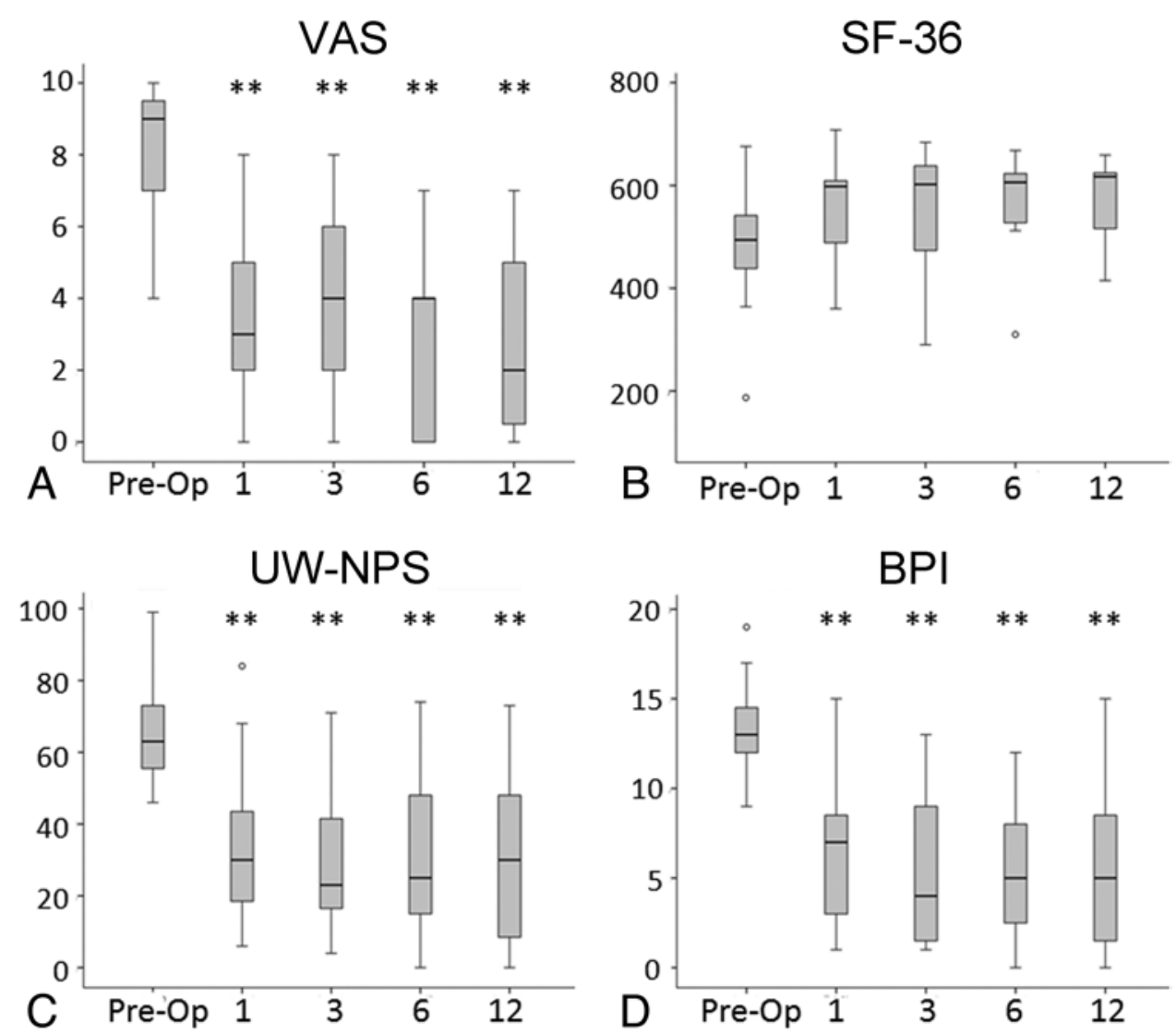

FIG. 1. Bar graphs showing overall outcomes according to the VAS (A), SF-36 (B), UWNPS (C), and BPI (D), preoperatively and at 1, 3,6, and 12 months after surgery. The median is indicated by the horizontal line inside the boxes, which represent 2 quartiles, and the whiskers show minimum and maximum values. Asterisks indicate the statistical significance of the difference between the postsurgery and presurgery scores. ${ }^{* *} p<0.01$ (highly statistically significant). Open circles indicate outliers.

significant $(\mathrm{p}<0.001)$ in both severity and interference domains.

\section{Discussion}

In this report we describe the second-largest recent, open-label, prospective study of DBS for pain, and the largest contemporary single-center experience of DBS for limb injury pain. Although not a new therapy, DBS has advanced considerably over the last two decades, concomitant with advances in both stimulator technology and neuroimaging techniques and, by corollary, improvements in efficacy and reductions in complications. Our results suggest that DBS can consistently deliver analgesia to patients with chronic neuropathic pain after amputation and BPA, with significant sustained improvements at 1 year. These results exceed those predicted by the Oxford experience that it has drawn upon. ${ }^{5}$ The authors attribute such success to refined patient selection within specific etiologies suggested to have better outcomes within larger heterogeneous case series. ${ }^{37,52,53}$ The study also likely benefited from the Oxford neurosurgeons' 15-year learning curve with DBS for pain, thus supporting an argument for only undertaking DBS for pain in centers with access to appropriate expertise and experience, and willing to audit outcomes per EFNS and NICE guidelines. ${ }^{9}$
Published peer-reviewed clinical outcomes data in DBS for pain case series comprising at least 6 patients were recently summarized elsewhere..$^{52,53}$ Since the pioneering studies of Mazars et al., Richardson and Akil, and Hosobuchi and Adams, and their long-term followup results published in the 1970s and 1980s, ${ }^{24,38,42,57}$ only about 20 groups worldwide have reported long-term efficacy in as many as $83 \%$ of patients with follow-up as long as 6 years. Just 5 centers published results in the last decade. $5,20,37,40,55,62$ Not all authors reported their failed trials that obviated full device implantation, however, leading to overestimation of efficacy in some reports. The literature is obfuscated by varying and simplistic outcome measures that preclude meaningful meta-analysis, such as verbal self-reports comprising only 3 or 5 categories.

Both phantom and stump pain after amputation, and BPA deafferentation pain, qualify as neuropathic pain under its latest definition. ${ }^{27}$ We decided to undertake ventroposterolateral rather than periventricular gray DBS, not because of the dogma that thalamic stimulation is more efficacious for nociceptive pain, ${ }^{3,37}$ but drawing upon the Oxford experience of using the ventroposterolateral nucleus of the sensory thalamus as a target with more clearly delineated intraoperative stimulation effects upon the awake or mildly sedated patient, less risk of side effects or morbidity from inaccuracy, and strong somatotopic lo- 
E. A. C. Pereira et al.

TABLE 3: Baseline scores and percentage improvement for amputation and BPA cohorts*

\begin{tabular}{|c|c|c|c|c|c|c|c|c|c|}
\hline \multirow[b]{2}{*}{ Variable } & \multicolumn{4}{|c|}{ Outcome Score } & \multicolumn{4}{|c|}{$\%$ Improvement } & \multirow[b]{2}{*}{$p$ Value } \\
\hline & Min & Max & Mean & SD & Min & Max & Mean & SD & \\
\hline \multicolumn{10}{|c|}{ amputation $(n=5)$} \\
\hline \multicolumn{10}{|c|}{ VAS } \\
\hline preop & 4 & 10 & 7.0 & 2.8 & & & & & \\
\hline $1 \mathrm{mo}$ & 0 & 7 & 2.8 & 2.6 & 30 & 100 & 65.3 & 25.0 & 0.026 \\
\hline 3 mos & 0 & 8 & 3.2 & 3.0 & 20 & 100 & 58.0 & 28.6 & 0.054 \\
\hline $6 \mathrm{mos}$ & 0 & 6 & 2.4 & 2.6 & -20 & 100 & 64.0 & 49.8 & 0.013 \\
\hline $12 \mathrm{mos}$ & 0 & 2 & 0.8 & 0.8 & 80 & 100 & 90.0 & 10.0 & 0.001 \\
\hline \multicolumn{10}{|l|}{ SF-36 } \\
\hline preop & 187 & 606 & 439 & 158 & & & & & \\
\hline $1 \mathrm{mo}$ & 602 & 708 & 634 & 44 & -0.7 & 242.3 & 71.4 & 98.1 & 0.013 \\
\hline 3 mos & 464 & 660 & 559 & 84 & -0.3 & 148.1 & 43.7 & 60.9 & 0.288 \\
\hline $6 \mathrm{mos}$ & 512 & 632 & 563 & 55 & -2.9 & 183.4 & 49.2 & 77.0 & 0.245 \\
\hline 12 mos & 458 & 659 & 579 & 87 & -1.52 & 230.0 & 57.5 & 97.9 & 0.127 \\
\hline \multicolumn{10}{|l|}{ UWNPS } \\
\hline preop & 53 & 99 & 72.2 & 17.3 & & & & & \\
\hline $1 \mathrm{mo}$ & 6 & 38 & 22.4 & 12.4 & 59 & 91 & 69.6 & 12.9 & $<0.001$ \\
\hline 3 mos & 12 & 41 & 25.2 & 14.1 & 46 & 81 & 66.2 & 14.3 & $<0.001$ \\
\hline $6 \mathrm{mos}$ & 0 & 25 & 16.0 & 12.1 & 55 & 100 & 77.6 & 18.3 & $<0.001$ \\
\hline 12 mos & 6 & 30 & 13.8 & 9.8 & 61 & 94 & 80.4 & 12.7 & $<0.001$ \\
\hline \multicolumn{10}{|l|}{$\mathrm{BPI}$} \\
\hline preop & 9 & 19 & 13.6 & 3.8 & & & & & \\
\hline $1 \mathrm{mo}$ & 1 & 8 & 4.0 & 2.7 & 58 & 91 & 72.8 & 12.7 & 0.001 \\
\hline $3 \mathrm{mos}$ & 1 & 13 & 4.2 & 5.1 & 7 & 93 & 69.6 & 35.6 & 0.001 \\
\hline $6 \mathrm{mos}$ & 0 & 9 & 3.8 & 3.6 & 36 & 100 & 70.0 & 28.5 & 0.001 \\
\hline 12 mos & 1 & 5 & 2.6 & 1.8 & 64 & 93 & 79.9 & 14.7 & $<0.001$ \\
\hline \multicolumn{10}{|l|}{$\operatorname{BPA}(n=6)$} \\
\hline \multicolumn{10}{|l|}{ VAS } \\
\hline preop & 8 & 10 & 9.0 & 0.6 & & & & & \\
\hline $1 \mathrm{mo}$ & 0 & 8 & 4.0 & 2.8 & 11 & 100 & 55.7 & 30.7 & $<0.001$ \\
\hline 3 mos & 1 & 8 & 4.7 & 2.6 & 11 & 89 & 48.8 & 27.0 & 0.001 \\
\hline $6 \mathrm{mos}$ & 0 & 7 & 3.2 & 2.7 & 30 & 100 & 66.1 & 28.1 & $<0.001$ \\
\hline $12 \mathrm{mos}$ & 0 & 7 & 4.3 & 2.9 & 22 & 100 & 52.7 & 30.2 & $<0.001$ \\
\hline \multicolumn{10}{|l|}{ SF-36 } \\
\hline preop & 364 & 676 & 508 & 104 & & & & & \\
\hline $1 \mathrm{mo}$ & 360 & 598 & 475 & 96 & -28.9 & 37.6 & -4.3 & 24.4 & 1.000 \\
\hline 3 mos & 290 & 684 & 553 & 149 & -36.1 & 74.4 & 11.7 & 37.7 & 1.000 \\
\hline $6 \mathrm{mos}$ & 310 & 668 & 559 & 131 & -31.7 & 73.6 & 13.3 & 36.0 & 1.000 \\
\hline 12 mos & 415 & 625 & 569 & 87 & -8.9 & 71.7 & 15.6 & 30.5 & 1.000 \\
\hline \multicolumn{10}{|l|}{ UWNPS } \\
\hline preop & 46 & 87 & 62.3 & 14.4 & & & & & \\
\hline $1 \mathrm{mo}$ & 8 & 84 & 44.5 & 28.1 & -33 & 88 & 28.3 & 41.1 & 0.415 \\
\hline $3 \mathrm{mos}$ & 4 & 71 & 36.8 & 25.2 & 6 & 94 & 41.8 & 33.2 & 0.055 \\
\hline $6 \mathrm{mos}$ & 0 & 74 & 46.3 & 26.9 & -17 & 100 & 23.7 & 41.2 & 0.648 \\
\hline $12 \mathrm{mos}$ & 0 & 73 & 44.3 & 25.2 & -16 & 100 & 26.2 & 40.8 & 0.399 \\
\hline \multicolumn{10}{|l|}{$\mathrm{BPI}$} \\
\hline preop & 12 & 17 & 13.5 & 1.9 & & & & & \\
\hline $1 \mathrm{mo}$ & 2 & 15 & 9.0 & 4.6 & -25 & 83 & 33.6 & 35.4 & 0.045 \\
\hline
\end{tabular}


Deep brain stimulation for amputation and brachial plexus pain

TABLE 3: Baseline scores and percentage improvement for amputation and BPA cohorts* (continued)

\begin{tabular}{|c|c|c|c|c|c|c|c|c|c|}
\hline \multirow[b]{2}{*}{ Variable } & \multicolumn{4}{|c|}{ Outcome Score } & \multicolumn{4}{|c|}{ \% Improvement } & \multirow[b]{2}{*}{$p$ Value } \\
\hline & Min & Max & Mean & SD & Min & Max & Mean & SD & \\
\hline \multicolumn{10}{|c|}{ BPA $(n=6)$ (continued) } \\
\hline \multicolumn{10}{|c|}{ BPI (continued) } \\
\hline 3 mos & 1 & 12 & 6.8 & 4.2 & 8 & 92 & 50.3 & 29.4 & 0.002 \\
\hline $6 \mathrm{mos}$ & 0 & 12 & 6.5 & 4.0 & 0 & 100 & 51.6 & 32.7 & 0.001 \\
\hline $12 \mathrm{mos}$ & 0 & 15 & 8.3 & 5.2 & -25 & 100 & 38.4 & 41.7 & 0.018 \\
\hline
\end{tabular}

* Min = minimum patient outcome score or percentage improvement within subgroup; Max = maximum patient outcome score or percentage improvement within subgroup.

$\dagger p$ value calculated on the difference between postsurgical and baseline scores. Statistically significant improvements $(p<0.05)$ in bold.

calization for appendicular pain syndromes. The success of this study leads us to advocate the ventroposterolateral nucleus of the sensory thalamus rather than periventricular gray as the first target of choice for a neurosurgeon commencing DBS for limb pain.

One limitation to this investigation that is similar to the late-twentieth century Medtronic trials of DBS for pain is a lack of randomization or case controls. ${ }^{7}$ However, other shortcomings of those trials have not affected this study, including a mix of heterogeneous cases, variable deep brain sites stimulated and stimulation parameter cycling, poor enrollment, and loss to follow-up. Nor have problems prevalent in the field of neuromodulation for chronic pain affected this study, including underspecified patient selection criteria and unblinded assessment of patient self-reported outcomes.

Neurosurgical treatments offered for BPA include dorsal root entry zone lesioning, with greatest improve-
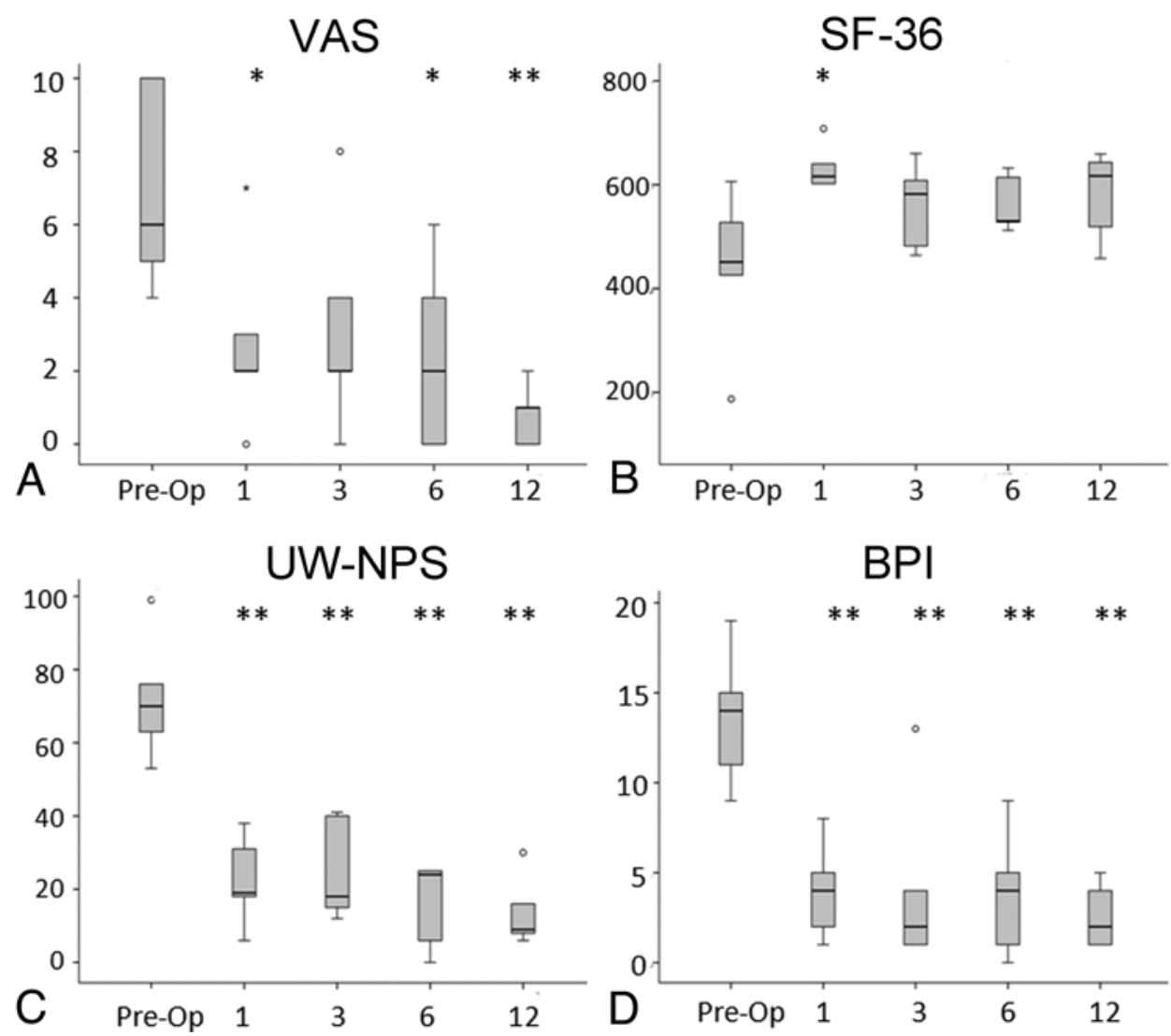

FIG. 2. Amputation subgroup outcomes according to the VAS (A), SF-36 (B), UWNPS (C), and BPI (D), before surgery (preop) and at 1, 3,6, and 12 months after surgery. The median is indicated by the horizontal line inside the boxes, which represent 2 quartiles, and the whiskers show minimum and maximum values. Asterisks indicate the statistical significance of the difference between the postsurgery and presurgery scores. ${ }^{*} p<0.05$ (statistically significant), ${ }^{* *} p<0.01$ (highly statistically significant). Open circles indicate outliers. 
E. A. C. Pereira et al.
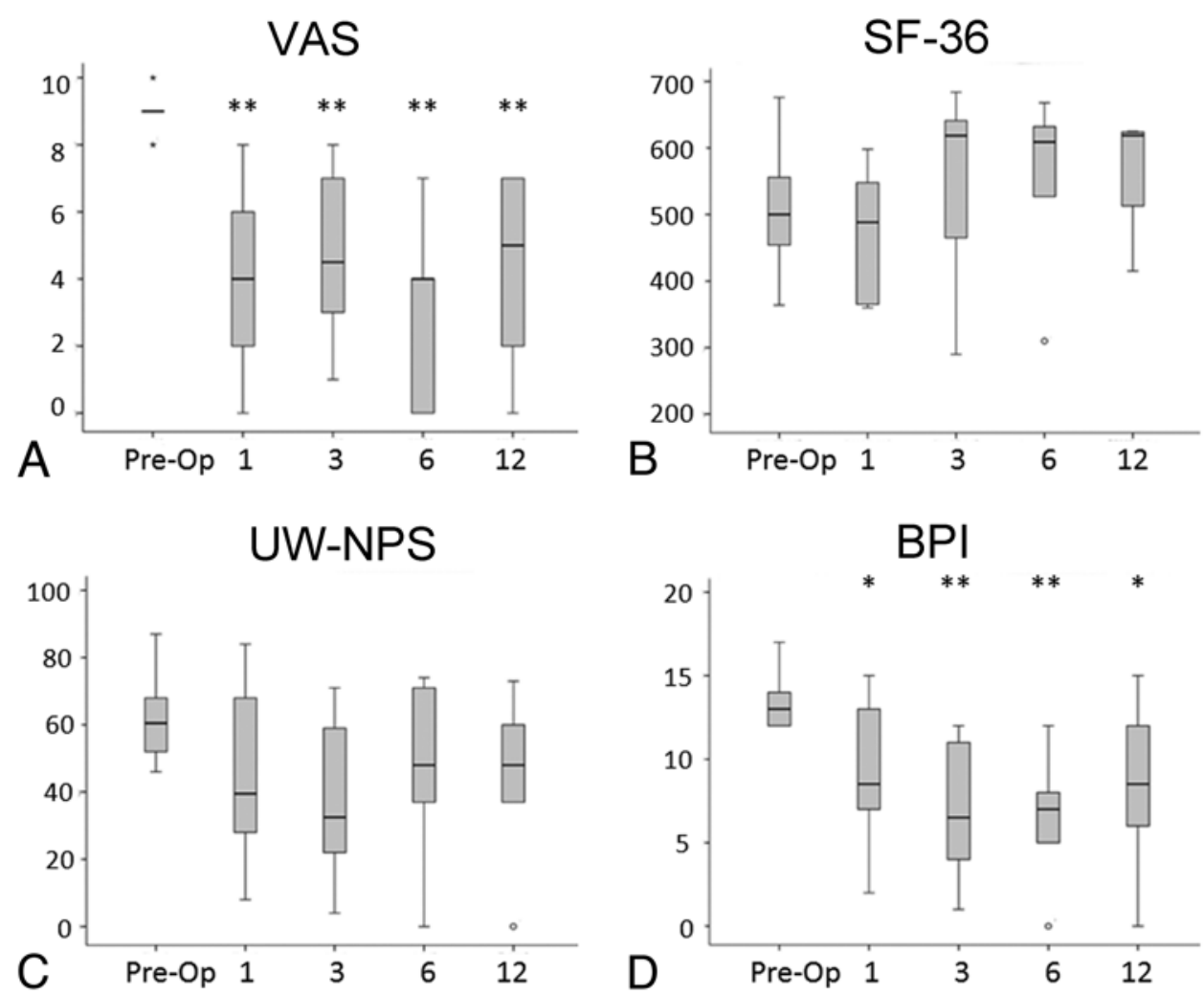

Fig. 3. Brachial plexus avulsion subgroup outcomes according to the VAS (A), SF-36 (B), UWNPS (C), and BPI (D), before surgery (pre-op) and at 1, 3, 6, and 12 months after surgery. The median is indicated by the horizontal line inside the boxes, which represent 2 quartiles, and the whiskers show minimum and maximum values. Asterisks indicate the statistical significance of the difference between the postsurgery and presurgery scores. ${ }^{*} p<0.05$ (statistically significant), ${ }^{* *} p<0.01$ (highly statistically significant). Open circles indicate outliers.

ments in paroxysmal pain; two-thirds of patients improved long term, yet as many as $10 \%$ experience dysesthesia and ipsilateral leg weakness. ${ }^{1,13,58}$ Motor cortex stimulation (MCS) has also been undertaken with equivocal results influencing paroxysms more than continuous pain, $, 2,33$ and spinal cord stimulation (SCS) has been reported with limited success. ${ }^{15,64}$ No trials comparing neuromodulation treatments for BPA have been reported. A small comparative case series of 19 amputees has suggested that DBS was superior to SCS and MCS in ameliorating phantom limb pain in $60 \%$ of patients versus $32 \%$ with SCS and $20 \%$ with MCS, with 2 patients with both DBS and MCS implanted experiencing better analgesia from DBS. ${ }^{30}$ Mazars et al. reported 5 patients with phantom limb pain whose pain disappeared after thalamic DBS. ${ }^{42}$ Other pioneers of DBS for pain such as Hosobuchi, Kumar, Young, and Levy, have all also reported improvements in phantom limb pain with DBS..$^{23,31,38,63}$ The Oxford cohort had VAS improvements at 1 year of $38.7 \%$ in 7 patients with phantom limb pain and $25.8 \%$ in 2 patients with BPA receiving a mixture of thalamic, periventricular gray, and dual-target DBS., ${ }^{4,5,44}$ Our single-center case series of 12 patients shows greater benefit at 1 year from ventroposterolateral DBS, in particular for amputation pain, suggesting that the therapy retains a role in these difficult-to-treat conditions. Randomized, blinded, controlled clinical trials are desirable, assessing the DBS both on and off, and in revisiting comparisons with other neuromodulatory therapies such as MCS and SCS alongside lesional treatments such as dorsal root entry zone.

An intriguing observation from the results presented here is the considerable and significant improvement in pain scores (VAS, UWNPS, or BPI), without an overall significant improvement in quality of life as measured by the SF-36. While improvements in physical function were noted, negligible improvements in social function, vitality, and emotional and mental health were reported. It is difficult to explain these results without undertaking further qualitative research by interviewing the patients, caregivers, and blinded pain physicians who undertook assessments. However, one can postulate first that pain relief alone in an already functionless limb may have contributed little to altering daily activities for the treated patients and, second, that the patient group who receive this treatment is so debilitated and incapacitated by chronic pain that the more social and emotional domains of their quality of life remain severely impaired despite being considerably improved by relief of pain in an affected limb. Further qualitative, social, and psychological research is desirable to analyze this unexpected finding.

Aside from its established anatomical involvement in pain processing from spinothalamic tracts to the insula, cingulate, and primary somatosensory cortex, the ventral posterior thalamus is implicated in central sensi- 


\section{Deep brain stimulation for amputation and brachial plexus pain}

tization and descending facilitation of aberrant circuitry in the pain neuromatrix by multiple lines of evidence. ${ }^{32,61}$ Specific mechanisms of central deafferentation and thalamocortical dysrhythmia that implicate sensory thalamic dysfunction in pain are suggested by nonhuman primate lesional and human functional imaging studies, and consequent thalamic reorganization can be large. ${ }^{26,28,39,50,54,60}$ Microelectrode recordings in patients with chronic pain have shown enhanced bursting activity and increased stump representation in amputees..$^{10,11,35}$ Patients in pain have characteristically enhanced low-frequency (8-15 $\mathrm{Hz}$ ) power spectra in ventroposterolateral deep brain macroelectrode local-field potentials. ${ }^{17}$ Magnetoencephalography has also implicated disruption of thalamocortical dysrhythmia in the analgesic mechanism of DBS, perhaps by its interrupting low-frequency oscillations and bursting activity. ${ }^{56}$ Ventroposterolateral DBS therefore appears to be a more pathophysiologically intuitive treatment than MCS and SCS for phantom limb and BPA deafferentation pain.

Both contemporary and older case series ${ }^{5,18}$ suggest that at least $25 \%$ of patients who find success during trial stimulation do not experience long-term success beyond 1 year after surgery. One reason (fortunately avoided here) is loss of patients at follow-up, which makes reaching statistical significance more challenging. Challenges are to identify predictors of long-term efficacy and investigate tolerance. Progressive increases of stimulus amplitude have proven unhelpful. ${ }^{31}$ Tolerance may be overcome by subtle alterations of either pulse width, frequency, or both, or failing that, breaks in stimulation. ${ }^{5}$ Importantly, the patients in the failed Medtronic trials and many other case series also received episodic cycling DBS, whereas our patients received continuous stimulation. Nevertheless, a subgroup remains either tolerant long term or demonstrates progressive reductions in efficacy. Hypotheses for these results include that patients genuinely become tolerant to the treatment, that a particular pain characteristic is reduced but others unmasked become worse over time, ${ }^{29}$ and that chronic pain exhibits disease progression concomitant with increasing severity despite DBS, as has been demonstrated in tremor. ${ }^{12}$ Advances in stimulator technology such as the development of demand-driven stimulators may enable patient-controlled analgesia and potentially overcome aspects of tolerance. Long-term follow-up of the patients in this cohort beyond 1 year will be important to adequately assess for tolerance phenomena.

Neuromodulation for neuropathic pain has resulted in positive experiences among physicians, high patient expectations, and positive case series, yet few randomized, controlled, clinical trials. ${ }^{8,36}$ From this promising prospective case-series experience, we encourage continued trials of this therapy for neuropathic pain after limb injury.

\section{Disclosure}

The Oxford authors acknowledge financial support from the UK Medical Research Council, Norman Collisson Foundation, Charles Wolfson Charitable Trust, and Oxford Comprehensive Biomedical Research Centre.

Author contributions to the study and manuscript preparation include the following. Conception and design: Pereira, Vaz, Aziz. Acquisition of data: Pereira, Linhares, Chamadoira, Rosas, Abreu, Rebelo, Aziz. Analysis and interpretation of data: Pereira, Boccard, Rebelo. Drafting the article: Pereira. Critically revising the article: Pereira, Boccard, Vaz, Aziz. Reviewed submitted version of manuscript: Pereira, Linhares, Chamadoira, Rosas, Rebelo, Vaz, Aziz. Approved the final version of the manuscript on behalf of all authors: Pereira. Statistical analysis: Boccard. Administrative/technical/material support: Pereira, Linhares, Chamadoira, Rosas, Abreu, Rebelo, Vaz, Aziz. Study supervision: Rebelo, Vaz, Aziz.

\section{Acknowledgments}

The Oxford authors thank Mrs. Liz Moir, R.G.N., and Mr. Alex Green, M.D., F.R.C.S.(SN), for invaluable advice regarding DBS for chronic pain. The authors thank Medtronic Portugal for assisting Dr. Pereira and Dr. Aziz with their visiting consultations.

\section{References}

1. Aichaoui F, Mertens P, Sindou M: Dorsal root entry zone lesioning for pain after brachial plexus avulsion: results with special emphasis on differential effects on the paroxysmal versus the continuous components. A prospective study in a 29-patient consecutive series. Pain 152:1923-1930, 2011

2. Ali M, Saitoh Y, Oshino S, Hosomi K, Kishima H, Morris S, et al: Differential efficacy of electric motor cortex stimulation and lesioning of the dorsal root entry zone for continuous vs paroxysmal pain after brachial plexus avulsion. Neurosurgery 68:1252-1258, 2011

3. Bittar RG, Kar-Purkayastha I, Owen SL, Bear RE, Green A, Wang S, et al: Deep brain stimulation for pain relief: a metaanalysis. J Clin Neurosci 12:515-519, 2005

4. Bittar RG, Otero S, Carter H, Aziz TZ: Deep brain stimulation for phantom limb pain. J Clin Neurosci 12:399-404, 2005

5. Boccard SG, Pereira EA, Moir L, Aziz TZ, Green AL: Longterm outcomes of deep brain stimulation for neuropathic pain. Neurosurgery 72:221-231, 2013

6. Cleeland CS, Ryan KM: Pain assessment: global use of the Brief Pain Inventory. Ann Acad Med Singapore 23:129-138, 1994

7. Coffey RJ: Deep brain stimulation for chronic pain: results of two multicenter trials and a structured review. Pain Med 2: 183-192, 2001

8. Coffey RJ, Lozano AM: Neurostimulation for chronic noncancer pain: an evaluation of the clinical evidence and recommendations for future trial designs. J Neurosurg 105:175189,2006

9. Cruccu G, Aziz TZ, Garcia-Larrea L, Hansson P, Jensen TS, Lefaucheur JP, et al: EFNS guidelines on neurostimulation therapy for neuropathic pain. Eur J Neurol 14:952-970, 2007

10. Davis KD, Kiss ZH, Luo L, Tasker RR, Lozano AM, Dostrovsky JO: Phantom sensations generated by thalamic microstimulation. Nature 391:385-387, 1998

11. Davis KD, Kiss ZH, Tasker RR, Dostrovsky JO: Thalamic stimulation-evoked sensations in chronic pain patients and in nonpain (movement disorder) patients. J Neurophysiol 75: 1026-1037, 1996

12. Favilla CG, Ullman D, Wagle Shukla A, Foote KD, Jacobson CE IV, Okun MS: Worsening essential tremor following deep brain stimulation: disease progression versus tolerance. Brain 135:1455-1462, 2012

13. Friedman AH, Nashold BS Jr, Bronec PR: Dorsal root entry zone lesions for the treatment of brachial plexus avulsion injuries: a follow-up study. Neurosurgery 22:369-373, 1988

14. Galer BS, Jensen MP: Development and preliminary validation of a pain measure specific to neuropathic pain: the Neuropathic Pain Scale. Neurology 48:332-338, 1997

15. Garcia-March G, Sánchez-Ledesma MJ, Diaz P, Yagüe L, Anaya J, Gonçalves J, et al: Dorsal root entry zone lesion ver- 
sus spinal cord stimulation in the management of pain from brachial plexus avulsion. Acta Neurochir Suppl (Wien) 39: $155-158,1987$

16. Gol A: Relief of pain by electrical stimulation of the septal area. J Neurol Sci 5:115-120, 1967

17. Green AL, Wang S, Stein JF, Pereira EA, Kringelbach ML, Liu X, et al: Neural signatures in patients with neuropathic pain. Neurology 72:569-571, 2009

18. Gybels JM, Sweet WH: Neurosurgical Treatment of Persistent Pain: Physiological and Pathological Mechanisms of Human Pain. Basel: Karger, Vol 11, 1989

19. Hall GC, Carroll D, Parry D, McQuay HJ: Epidemiology and treatment of neuropathic pain: the UK primary care perspective. Pain 122:156-162, 2006

20. Hamani C, Schwalb JM, Rezai AR, Dostrovsky JO, Davis KD, Lozano AM: Deep brain stimulation for chronic neuropathic pain: long-term outcome and the incidence of insertional effect. Pain 125:188-196, 2006

21. Heath R: Studies in Schizophrenia: A Multidisciplinary Approach to Mind-Brain Relationships. Cambridge, MA: Harvard University Press, 1954

22. Heath RG, Mickle WA: Evaluation of seven years' experience with depth electrode studies in human patients, in Ramey ER, O'Doherty DS (eds): Electrical Studies on the Unanaesthetized Brain. New York: Paul B Hoeber, 1960, pp 214-247

23. Hosobuchi Y: Subcortical electrical stimulation for control of intractable pain in humans. Report of 122 cases (1970-1984). J Neurosurg 64:543-553, 1986

24. Hosobuchi Y, Adams JE, Linchitz R: Pain relief by electrical stimulation of the central gray matter in humans and its reversal by naloxone. Science 197:183-186, 1977

25. Hosobuchi Y, Adams JE, Rutkin B: Chronic thalamic stimulation for the control of facial anesthesia dolorosa. Arch Neurol 29:158-161, 1973

26. Jain N, Qi HX, Collins CE, Kaas JH: Large-scale reorganization in the somatosensory cortex and thalamus after sensory loss in macaque monkeys. J Neurosci 28:11042-11060, 2008

27. Jensen TS, Baron R, Haanpää M, Kalso E, Loeser JD, Rice AS, et al: A new definition of neuropathic pain. Pain 152:22042205, 2011

28. Jones EG: Cortical and subcortical contributions to activitydependent plasticity in primate somatosensory cortex. Annu Rev Neurosci 23:1-37, 2000

29. Kamano S: Author's experience of lateral medullary infarction-thermal perception and muscle allodynia. Pain 104:4953,2003

30. Katayama Y, Yamamoto T, Kobayashi K, Kasai M, Oshima H, Fukaya C: Motor cortex stimulation for phantom limb pain: comprehensive therapy with spinal cord and thalamic stimulation. Stereotact Funct Neurosurg 77:159-162, 2001

31. Kumar K, Toth C, Nath RK: Deep brain stimulation for intractable pain: a 15-year experience. Neurosurgery 40:736-747, 1997

32. Lee MC, Zambreanu L, Menon DK, Tracey I: Identifying brain activity specifically related to the maintenance and perceptual consequence of central sensitization in humans. J Neurosci 28:11642-11649, 2008

33. Lefaucheur JP, Drouot X, Cunin P, Bruckert R, Lepetit H, Créange A, et al: Motor cortex stimulation for the treatment of refractory peripheral neuropathic pain. Brain 132:1463-1471, 2009

34. Lenz FA, Dostrovsky JO, Tasker RR, Yamashiro K, Kwan HC, Murphy JT: Single-unit analysis of the human ventral thalamic nuclear group: somatosensory responses. J Neurophysiol 59: 299-316, 1988

35. Lenz FA, Kwan HC, Dostrovsky JO, Tasker RR: Characteristics of the bursting pattern of action potentials that occurs in the thalamus of patients with central pain. Brain Res 496: 357-360, 1989
36. Levy R, Deer TR, Henderson J: Intracranial neurostimulation for pain control: a review. Pain Physician 13:157-165, 2010

37. Levy RM: Deep brain stimulation for the treatment of intractable pain. Neurosurg Clin N Am 14:389-399, vi, 2003

38. Levy RM, Lamb S, Adams JE: Treatment of chronic pain by deep brain stimulation: long term follow-up and review of the literature. Neurosurgery 21:885-893, 1987

39. Llinás RR, Ribary U, Jeanmonod D, Kronberg E, Mitra PP: Thalamocortical dysrhythmia: a neurological and neuropsychiatric syndrome characterized by magnetoencephalography. Proc Natl Acad Sci U S A 96:15222-15227, 1999

40. Marchand S, Kupers RC, Bushnell MC, Duncan GH: Analgesic and placebo effects of thalamic stimulation. Pain 105: 481-488, 2003

41. Mark VH, Ervin FR: Role of thalamotomy in treatment of chronic severe pain. Postgrad Med 37:563-571, 1965

42. Mazars GJ, Merienne L, Cioloca C: Comparative study of electrical stimulation of posterior thalamic nuclei, periaqueductal gray, and other midline mesencephalic structures in man, in Bonica JJ, Liebeskind JC, Albe-Fessard DG (eds): Advances in Pain Research and Therapy. New York: Raven Press, 1979, pp 541-546

43. Melzack R, Wall PD: Pain mechanisms: a new theory. Science 150:971-979, 1965

44. Nandi D, Yianni J, Humphreys J, Wang S, O'sullivan V, Shepstone B, et al: Phantom limb pain relieved with different modalities of central nervous system stimulation: a clinical and functional imaging case report of two patients. Neuromodulation 7:176-183, 2004

45. Narakas A: Surgical treatment of traction injuries of the brachial plexus. Clin Orthop Relat Res 133:71-90, 1978

46. National Institute for Health and Care Excellence: IPG382. Deep Brain Stimulation for Chronic Pain Syndromes (Excluding Headache). (http://publications.nice.org.uk/deepbrain-stimulation-for-refractory-chronic-pain-syndromesexcluding-headache-ipg382). [Accessed July 25, 2013]

47. Olds J, Milner P: Positive reinforcement produced by electrical stimulation of septal area and other regions of rat brain. $\mathbf{J}$ Comp Physiol Psychol 47:419-427, 1954

48. Parry CB: Pain in avulsion of the brachial plexus. Neurosurgery 15:960-965, 1984

49. Parry CB: Pain in avulsion lesions of the brachial plexus. Pain 9:41-53, 1980

50. Pereira EA, Green AL, Bradley KM, Soper N, Moir L, Stein JF, et al: Regional cerebral perfusion differences between periventricular grey, thalamic and dual target deep brain stimulation for chronic neuropathic pain. Stereotact Funct Neurosurg 85:175-183, 2007

51. Pereira EA, Green AL, Nandi D, Aziz TZ: Deep brain stimulation: indications and evidence. Expert Rev Med Devices 4:591-603, 2007

52. Pereira EAC, Aziz TZ: Deep brain stimulation, in Hayek S, Levy RM, Deer TR (eds): Neurostimulation for the Treatment of Chronic Pain. Interventional and Neuromodulatory Techniques for Pain Management, Vol 1. Philadelphia: Elsevier Saunders, 2011, pp 187-201

53. Pereira EAC, Moir L, Green AL, Aziz TZ: Deep brain stimulation for chronic pain, in Krames E, Peckham PH, Rezai AR (eds): Neuromodulation, Vol 1. London: Elsevier, 2009, pp 499-507

54. Ralston HJ III: Pain and the primate thalamus. Prog Brain Res 149:1-10, 2005

55. Rasche D, Rinaldi PC, Young RF, Tronnier VM: Deep brain stimulation for the treatment of various chronic pain syndromes. Neurosurg Focus 21(6):E8, 2006

56. Ray NJ, Jenkinson N, Kringelbach ML, Hansen PC, Pereira EA,Brittain JS, et al: Abnormal thalamocortical dynamics may be altered by deep brain stimulation: using magnetoencephalography to study phantom limb pain. J Clin Neurosci 16: 32-36, 2009 


\section{Deep brain stimulation for amputation and brachial plexus pain}

57. Richardson DE, Akil H: Long term results of periventricular gray self-stimulation. Neurosurgery 1:199-202, 1977

58. Sindou MP, Blondet E, Emery E, Mertens P: Microsurgical lesioning in the dorsal root entry zone for pain due to brachial plexus avulsion: a prospective series of 55 patients. J Neurosurg 102:1018-1028, 2005

59. Torrance N, Smith BH, Bennett MI, Lee AJ: The epidemiology of chronic pain of predominantly neuropathic origin. Results from a general population survey. J Pain 7:281-289, 2006

60. Walton KD, Dubois M, Llinás RR: Abnormal thalamocortical activity in patients with Complex Regional Pain Syndrome (CRPS) type I. Pain 150:41-51, 2010

61. Woolf CJ, Salter MW: Neuronal plasticity: increasing the gain in pain. Science 288:1765-1769, 2000

62. Yamamoto T, Katayama Y, Obuchi T, Kano T, Kobayashi K, Oshima $\mathrm{H}$, et al: Thalamic sensory relay nucleus stimulation for the treatment of peripheral deafferentation pain. Stereotact Funct Neurosurg 84:180-183, 2006

63. Young RF, Rinaldi PC: Brain stimulation, in North RB, Levy RM (eds): Neurosurgical Management of Pain. New York: Springer-Verlag, 1997, pp 283-301
64. Zorub DS, Nashold BS Jr, Cook WA Jr: Avulsion of the brachial plexus. I. A review with implications on the therapy of intractable pain. Surg Neurol 2:347-353, 1974

Manuscript submitted February 4, 2013.

Accepted July 9, 2013.

Please include this information when citing this paper: DOI: 10.3171/2013.7.FOCUS1346.

Supplemental online information:

Video: http://mfile.akamai.com/21490/wmv/digitalwbc.download. akamai.com/21492/wm.digitalsource-na-regional/focus13-46_ video_1.asx (Media Player).

http://mfile.akamai.com/21488/mov/digitalwbc.download.akamai. com/21492/qt.digitalsource-global/focus13-46_video_1.mov (Quicktime).

Address correspondence to: Erlick A. C. Pereira, D.M., Oxford Functional Neurosurgery, Department of Neurological Surgery, The West Wing, John Radcliffe Hospital, Oxford OX3 9DU, United Kingdom.email: eacp@eacp.co.uk. 